\title{
MODEL DRIVEN HEALTHCARE: DISCONNECTED PRACTICES
}

\author{
Tillal Eldabi \\ Brunel University \\ Brunel Business School \\ Uxbridge, Middx, UB8 3PH, UK \\ Con Connell \\ Jonathan H. Klein \\ University of Southampton \\ School of Management \\ Southampton, SO17 1BJ, UK
}

Gyuchan T. Jun

John Clarkson

University of Cambridge

Engineering Design Centre

Cambridge, CB2 1PZ, UK

\begin{abstract}
Over the past decades simulation has been recognized as a vital tool for solving problems within the healthcare sector, almost catching up with other areas. It is evident that healthcare systems are rapidly evolving into complex and dynamic environments whilst bearing a multitude of stakeholders. Simulation has originally emerged from military and manufacturing applications that mainly follow sequential processing with pre-specified targets. Such an approach is too rigid and irrelevant to the complexity and dynamism of healthcare systems, where lack of understanding is a common feature. This is mainly attributed to lack of understating of the life cycle of healthcare services. In this paper we attempt to define the life cycle of healthcare services and explore the use of modeling and simulation in supporting healthcare service development and management. We particularly explore a number of exemplars of how modeling was used to support earlier stages of the service life cycle.
\end{abstract}

\section{INTRODUCTION}

The evident mismatch between modeling theories and the nature of healthcare problems continues to be the biggest source of barriers to implementing and appreciating the value of modeling to healthcare. Model driven healthcare is a term which originates from a joint research effort (Eldabi 2009) that remains resolute - despite the continued disappointments of using modeling in healthcare - that modeling and simulation should be the key drivers in making within healthcare. Healthcare systems and operations would work better if they are driven by model-informed decisions - as opposed to on-the-hoof decisions. That is to say there is a need for a more comprehensive modeling environment that follows the decision making process from the inception of the idea to final implementation (vision building, design, development, management, and evaluation).

There is no scarcity in the use of modeling and simulation in healthcare. In fact, utilization of simulation techniques in the healthcare arena has increased dramatically within the past 10 years. Royston (2005) in his presentation at the MASHnet launch - revealed an exponential trend in publications. This trend is clearly evident in Jun, Jacobson, and Swisher (1999) who reported only 8 studies in simulation of 
health clinics between 1973 and 1977 and 28 studies between 1993 and 1997 . Similarly, a search on the use of System Dynamics in healthcare by Brailsford (2008), found a rapidly increasing trend. This is also common to all other methods. A common feature in most of the published cases is that they tend to focus on individual specialties or isolated sub-systems (such as, accident and emergency (A\&E), theatre utilization, outpatient clinics and so on) as reported by many authors. There have not been much publications on cases to do with multi-agency modeling, despite the fact that in a typical healthcare setting systems are usually represented by multi-agency and complexity, in addition to being owned by multiple stakeholders, such as those mentioned in by Jun, Jacobson, and Swisher (1999) and Lehaney and Paul (1996). There is an obvious mismatch between the silo based models and targeted multi-agency systems. The widely admitted lack of implementation of simulation studies remains a testimonial to such mismatch (Eldabi, Paul, and Young 2007). This is in addition to the mismatch between modeling approaches and the nature of healthcare problems as indicated by Eldabi (2009). Similarly, there is a clear lack of reporting on long term modeling, along the system life cycle.

Having explored the first two mismatches previously, here we are focusing on the third mismatch. Most modelers and stakeholders seem to focus their attention on using modeling to solve a specific problem. Such problems are usually time and context bound. However, a typical service (or a product) usually go through a life cycle, starting by initiating the need(s) for it and usually ending with a set of fresh needs for an improved service or an altogether new service. What we find is that current approaches are dedicated to a specific point in the life cycle of the service. Even though there are many techniques that can be used for each of the stages in the life cycle, these usually are disconnected with modeling starting from scratch at each stage. In this paper we are attempting to profile the life cycle of a typical healthcare service and the modeling requirements for each stage in the life cycle. More attention will then be given to the techniques relevant to the first stage and how outcomes of such techniques could be used as precursors for modeling within the following stages.

\section{SERVICE DEVELOPMENT LIFE CYCLE}

This section aims to explore and identify the concept of "service development cycle" in general, followed by mapping the general concept on healthcare services life cycle. It must be noted that in this paper we opted to regard care provision as a service rather than a product based on the comparison conducted by Johne and Storey (1998), who differentiate between service and products using three criteria: Tangibility, services are intangible and cannot be easily measured, while products are usually tangible. Heterogeneity, services are heterogeneous and may differ from one item to the other based on the supplier and the receiver, while products have the tendency to be uniform and homogeneous. Simultaneity, services are typically produced and consumed simultaneously and cannot be stocked, while products could be produced and stocked for late consumption. Based on these criteria it is derived that care provision can be considered as a service given its intangibility, heterogeneity, and simultaneity. Healthcare do have products such as drugs, diagnostic tools, and medicine, however, the main element of healthcare is care giving, hence the focus of this paper.

\subsection{New Service Development Life Cycle}

In order to be able to profile the life cycle of healthcare services, the following discussion starts by scoping the general concept of service development life cycle. Johne and Storey (1998) conducted a thorough review of new service development. In their review, Johne and Storey have categorized service development life cycle into three stages. Table 1 present these stages and the corresponding components of each stage. Stage 1 of the life cycle is to do with initialing the need building ideas for meeting such needs. This is mainly a conceptual stage but relies significantly on the consensus of stakeholders. Stage 2 is where the target service is specified in more detail and put together. At this stage the service, although still offline, goes through a series of experimentation to assess its viability. Decision makers would be 
concerned with getting the service right. Stage 3 is where the service goes live. At this stage the focus will be on maintaining the soundness of the service and the returns on investment.

Table 1: Stages of New Service Development (adapted from Johne and Storey (1998)

\begin{tabular}{|c|c|c|}
\hline \multicolumn{3}{|l|}{ Stage 1} \\
\hline $\begin{array}{ll}\text { - } & \text { New product strategy } \\
\text { - } & \text { Idea generation } \\
\text { - } & \text { Screening and evaluation }\end{array}$ & $\begin{array}{l}0 \\
0\end{array}$ & $\begin{array}{l}\text { Identify the strategic business requirements that the new product } \\
\text { should satisfy. Mainly based on a market gap or innovative ideas. } \\
\text { Search for product ideas to meet strategic objectives. } \\
\text { A quick analysis of ideas made against criteria that reflect the ob- } \\
\text { jectives of the organization }\end{array}$ \\
\hline \multicolumn{3}{|l|}{ Stage 2} \\
\hline $\begin{array}{ll} & \text { Business analysis } \\
\text { - } & \text { Development } \\
\text { - } & \text { Testing }\end{array}$ & 0 & $\begin{array}{l}\text { A detailed analysis of the attractiveness of an idea in business terms } \\
\text { Translation of the idea into an actual product for the market } \\
\text { The commercial experiments necessary to verify earlier business } \\
\text { judgments }\end{array}$ \\
\hline \multicolumn{3}{|l|}{ Stage 3} \\
\hline - $\quad$ Commercialization & 0 & The when, where, to whom and how decisions of the launch \\
\hline
\end{tabular}

\subsection{Mapping of Phases of Healthcare Systems Development}

This section is aiming to profile and identify the main stages of service development within healthcare organizations. The profiling will be based on the information provided in Table 1. Each stage will include a brief description of the modeling requirements.

\subsubsection{Stage 1: Inception}

Healthcare systems are mainly devoted to cater for local and/or national needs. Hence, it is very important when designing a new service, or modifying an existing one, to identity the consumers' needs and the measures that go with it. Once such needs have been identified, the next step is to draw up a service that meets those needs and to predict the specific demand for such a service. Decisions at this stage are either taken at the policy or strategic level. Not much precision is required here, rather the decision becomes one of identifying the type and general direction of the service. This stage is mainly about innovation and ideas generation. It is driven by consumers' needs but could also be driven by national targets and influences from funding bodies and other pressure groups. Healthcare organizations are becoming more and more competitive which makes them very keen to innovate. In summary this stage covers identifying a problem (or gap) and coming up with innovative suggestions to solve it.

As mentioned earlier healthcare systems are characterized by multiple ownership and complexity. In order to make decisions that involve change or significant investment, more effort should be spent on coordinating the differing views and needs of the stakeholders concerned, the role of modeling at this stage relates mainly to ideas generation and consensus building.

\subsubsection{Stage 2: Development}

Once a decision is made regarding which service to develop, Stage 2 is about designing and developing the new service or modifying an existing one. Ideas generated at Stage 1 are expanded and implemented at Stage 2. Most new service development (NSD) literature (Menor, Tatikonda, and Sampson 2002) tend to distinguish between design and development. However, and for the purpose of healthcare and modeling, these would be amalgamated in one stage to reflect the use of modeling in designing as part of developing new services. The most important element to get to grips with at this stage is the availability and the best use of resources to support the new service. Hence, most activities at this stage are concerned with resource allocation and utilization, i.e., the choice will be dependent on which service will consume less resources and more efficiently. Obviously measures here include health outcomes as the main driver 
and not solely dependent on the value for money. Typically this is one of the main features that differentiates healthcare systems from other systems.

Modeling at Stage 2 is used to design new services and to evaluate alternative design options and yields on resources. More precision is required at this stage to provide more quantitative and ordinal measures. It must be noted that multiple ownership is still a prominent feature at this level. Most of the decisions - although may involve policy and strategic levels - are taken at the operational levels and they are about specific results.

\subsubsection{Stage 3: Management}

This stage is about maintaining a smooth delivery of a satisfactory and competitive service. The role of the decision makers is to monitor and continuously evaluate the service and prevent deviation and arising problems. These may include high maintenance cost, low health outcomes, decreased staff morale and so on. Decision makers may impose certain managerial actions to make sure the process is working well and will also device plans to assess the service. For major decisions where modeling is usually required decision makers are usually faced with 2 options. First is to impose major changes to the system, this occurs when the existing service is meeting the right demand but not efficiently. On the other hand, decision makers may resort to completely developing a new service. This may be caused by rising demands for new services or the fact that the existing service becomes obsolete.

When it is about modifying existing services, more accurate modeling is sought to find out how new components would fit within the existing system. Accuracy is also supported by the existence of data within the system. The cycle then comes back to Stage 1 if a new service sought.

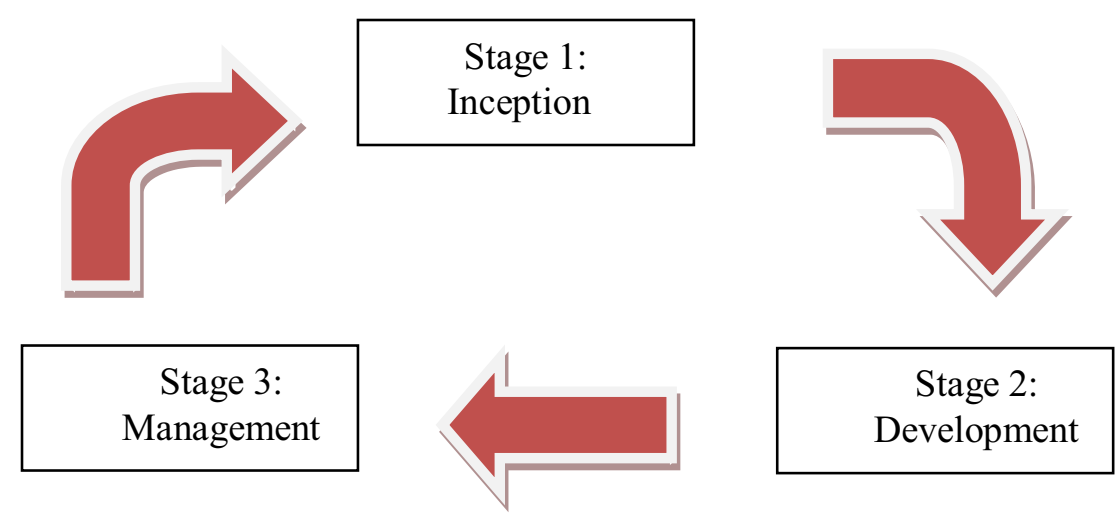

Figure 1: Healthcare Service Development Life Cycle

\section{STAGE 1 MODELING APPROACHES}

Most of the literature on modeling and simulation in healthcare tends to describe models for Stages 2 and 3 and, to a large extent, draw some similarities and linkages between the 2 stages. That is, models are for evaluating alterative scenarios during the design phase or during operational phase. Most of these models tend to look for accurate representations of the system whilst aiming to achieve specific outputs. Approaches to modeling at Stage 1, and due to nature of requirements, tend to seek consensus rather than outputs. The expected outcome from these models create a barrier between models at Stage 1 and those used within Stages 2 and 3. This disconnection is so deep that some of the modeling communities do not recognize the benefits of linking such methods, with some exceptions such as the article by Pidd (2007). We feel that, and for the cycle to be complete, it is important to eliminate the disconnection between models of Stage 1 and those of Stage 2. Given the expansive literature on hard modeling approaches used 
for Stage 2, the following discussion turn the attention on some approaches used for Stage 1, aiming to highlight the benefits of such approaches to the service development life cycle.

\subsection{Narrative and Problem Structuring Methods}

There are at least two aspects, peculiar to Problem Structuring Methods (PSM) used, that encourage this enhanced appreciation.

The first, and perhaps most obvious, is the graphical nature of many such approaches; the user community can 'see' the problem, often in a way that had not previously been possible. More importantly, the relationships between elements of the problem become more visible. Taking as an example the use of Rich Pictures in SSM (Checkland 1981, Checkland and Scholes 1990), where the approach seeks to deliberately make explicit possible areas of conflict between stakeholders, such that these are then explored in the forum of debate that SSM facilitates. The intention is often not to attempt to 'solve' such tensions which might be organizationally very deep-seated, for example - but to formally acknowledge their role in the problem situation that the modeling is seeking to address. This way of 'surfacing' tensions in a graphical manner at Stage 1, rather than the sometimes-preferred alternative of 'well, let's sort that out later, once the model has been built' offers its own challenges, but also offers one valuable way in which PSMs can be used at the earliest possible stage of modeling.

A second advantage that PSM modeling might promote is that it encourages dialog as an essential medium of knowledge exchange. Shared knowledge about any situation is inevitably partial, and the healthcare profession is no exception. One might argue that, in view of the ways in which the provision of clinical and non-clinical healthcare is sometimes structured, the tendency for partial knowledge is organizationally reinforced. Little work has been undertaken to explore the impact of such boundarycrossing knowledge sharing which might be particularly promoted by the use of PSM; the extensive Community of Practice literature (for example, Wenger 1998), tends to focus on communities of likeminded, rather than disparately-minded members. One possible way in which PSM might promote knowledge sharing that crosses such boundaries is by the use of narratives. There is a growing recognition of the role that narratives have to play in the exchange of organization knowledge (Connell, Klein, and Meyer 2004; Klein, Connell, and Meyer 2007). A value of their use in PSMs might be twofold; to help all parties appreciate the strength of feeling about a particular issue - often better expressed through a story of an event along the lines of -'did I tell you about the time when a patient nearly died because........'. The second value, arising from the first, is the way in which the shared knowledge might then be modified through a counter-story, which might support or contradict the first story - 'that reminds me of the time when, if only we had been able to......'. An outcome of this is the co-creation of new (sometimes only implicit) stories in which a change in practice, say, might have led to a change in outcome ('If only we had had a system which allowed us to do........').

One of the important characteristics of stories - that they are often very memorable - can serve to support PSMs not only during their early use, but also throughout the duration of any modeling intervention, perhaps providing a useful shorthand that serves to remind users of what it is they are trying to achieve through the modeling.

\subsection{Graphical elicitation}

Graphical elicitation is a relatively new terminology employed to specifically describe the use of diagrammatic representations as information elicitation stimuli in interviews (Crilly, Clarkson, and Blackwell 2006). In this paper, we denote graphical elicitation as the use of diagrammatic representations as information elicitation stimuli for problem understanding and communication, but not necessarily limited to interviews. In fact, and as mentioned earlier, many problem structuring methods include an element of diagrammatic representations as a part of their problem structuring processes. In addition the importance of visual interaction and animation in modeling and simulation approaches has been highlighted whilst visual aspects of commercial simulation software tools have been greatly improved. However, graphical 
modeling exists as a separate discipline and we believe that more from this discipline can be exploited for problem understanding and communication.

Two examples are presented below to show some diagrammatic representation methods and their potentials for healthcare service development and management. The two examples were derived from a participatory observation of a three-month healthcare organization consulting project, which aimed to achieve productive patient discharge. The workshops and interviews were mainly used for problem understanding, idea generation and evaluation in this project. One of the authors (G. Jun) observed the consulting (problem solving) process to find out the potential of graphical elicitation approaches. Issue mapping and systems modeling methods, more specifically state machine diagrams, were applied.

\subsubsection{Issue mapping}

Issue maps are based on a graphical modeling language called IBIS (Issue Based Information System). Kunz and Rittel (1970) pioneered the rationale capturing approach to communicate the structure of the complex issues. The basic concept of IBIS is simple. It is a directed graph, where some nodes represent three basic elements - questions, ideas and pro/con arguments, and are linked by arcs to other nodes. Issue maps provide an open and systematic way to clarify diverse perspectives, conflicting interpretations and goals, and inconsistent information. Issue maps have been most effectively implemented in the context of facilitated meeting to create diagrams that capture and connect participants' comments particularly when handling wicked problems with both social and technical complexity (Conklin et al. 2001). Recently, the potential of the issue maps for the rationale capture in the design of complex engineering systems has been highlighted by Bracewell and Wallace (2003) and they have been increasingly applied to engineering design practices ever since. The use of issue maps in healthcare has rarely been published in academic journals, however, there is more potential through some pilot trials and good reception from healthcare practitioners especially at Stage 1 of service development.

Figure 2 shows issues (problems, requirements, options and arguments) around productive patient discharge and provides a structure for problem understanding, concept generation and concept evaluation. This can eventually help define appropriate scope and clarify further questions for more specific modeling and simulation when required.

\subsubsection{Systems Modeling Language}

The second example is a general-purpose graphical systems modeling language (SysML: Systems Modeling Language). SysML has been developed to support the analysis, specification, design, verification and validation of man-made and natural complex systems including hardware, software, data, personnel, procedures and facilities. SysML consists of nine diagrams as shown in Figure 3 and can represent systems, components and other entities such as functions, messages, states, constraints and requirements.

In healthcare, various names were used to describe diagrammatic representation such as patient journeys, care pathways and process maps, but all of them are minor variants of activity diagrams. Some other diagrams such as sequence diagrams were applied in healthcare, but only in isolated situations and without overall consideration of alternative modeling methods. The need has been raised for better application of graphical systems modeling approaches to the design of healthcare systems (Clarkson et al. 2004). In response, Jun, Ward, and Clarkson (2010) developed a more detailed diagram type categorization framework for healthcare application and evaluated the usability and utility to healthcare professionals.

For the productive patient discharge project, state machine diagrams, i.e. a state transition diagram, which had been hardly used in healthcare, were applied. Figure 4 represents patient-related states such as patient's location and patient's physical status, and transition conditions and actions between them. As found in the previous research (Jun, Ward, and Clarkson 2010), state machine diagrams are very effective 
in describing care processes from patient perspectives and highly efficient in describing complex and long care processes in a compact manner.

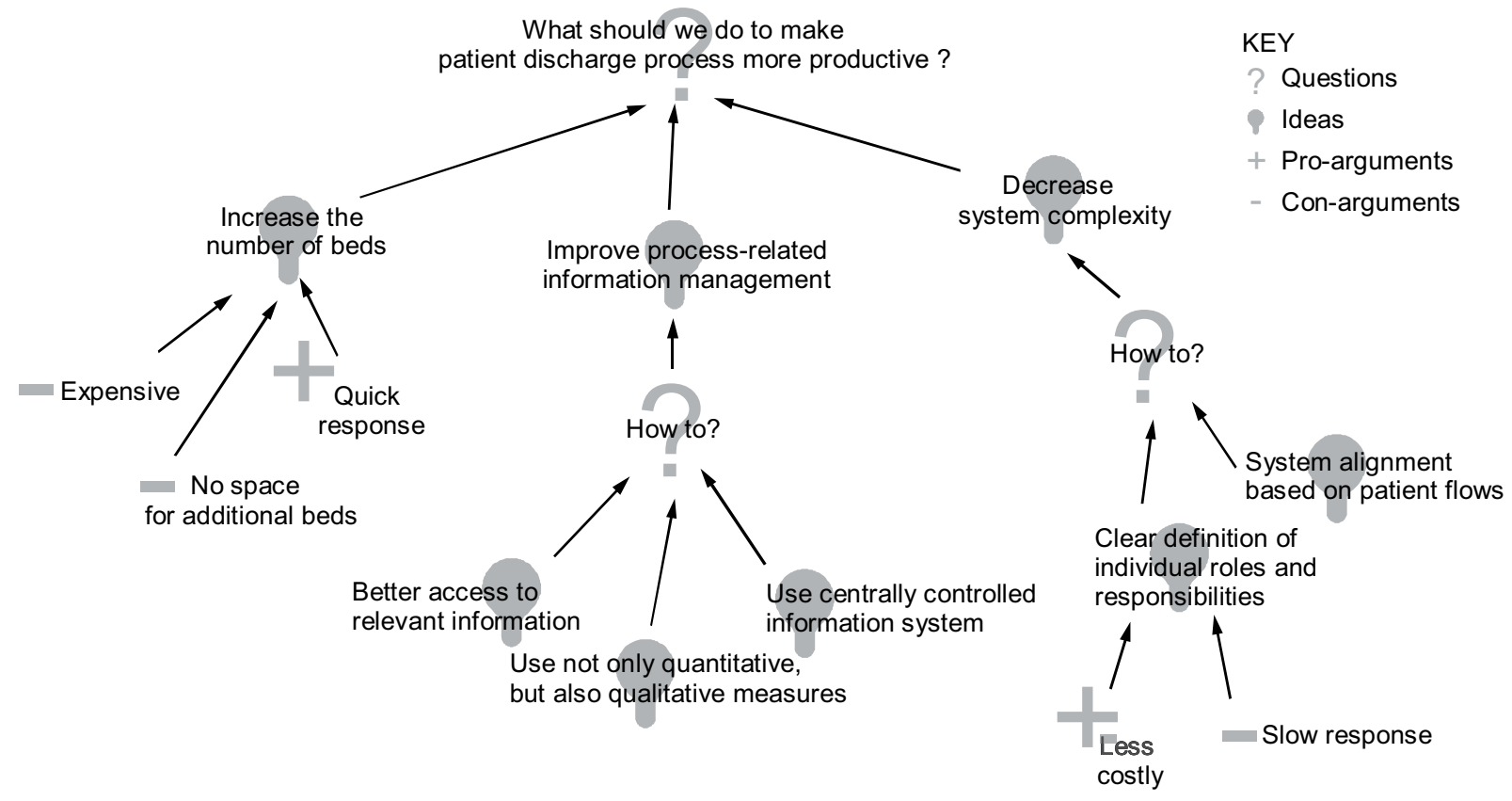

Figure 2: Issue map for making productive patient discharge

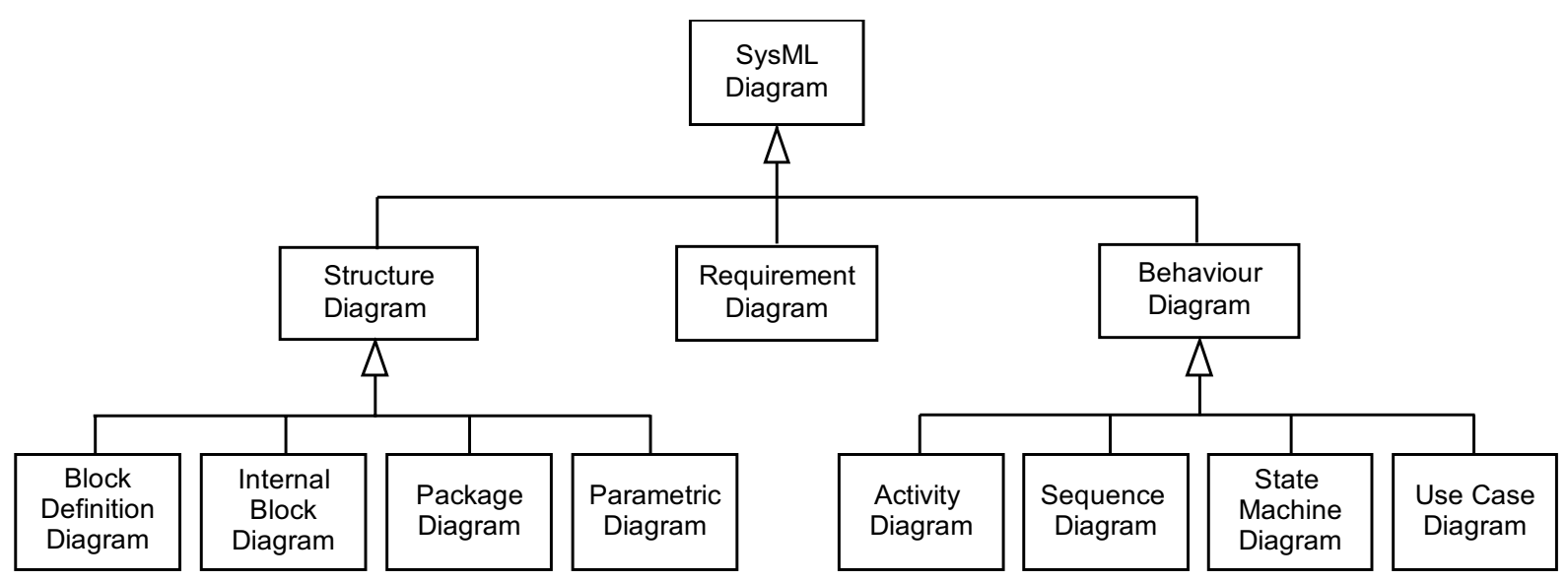

Figure 3: Nine diagram types of SysML (Friedenthal et al., 2008)

\section{THE MODELING PROCESS FOR STAGE 1}

Given the delicate nature of Stage 1 and the nature of the modeling approaches used, it is inevitable that the modeling process itself will be different from those of Stage 2. This is particularly the case when dealing with stakeholders and the nature of expected outcomes. This section discussions these two issues in more detail in order to complete the picture of modeling at Stage 1. 
KEY

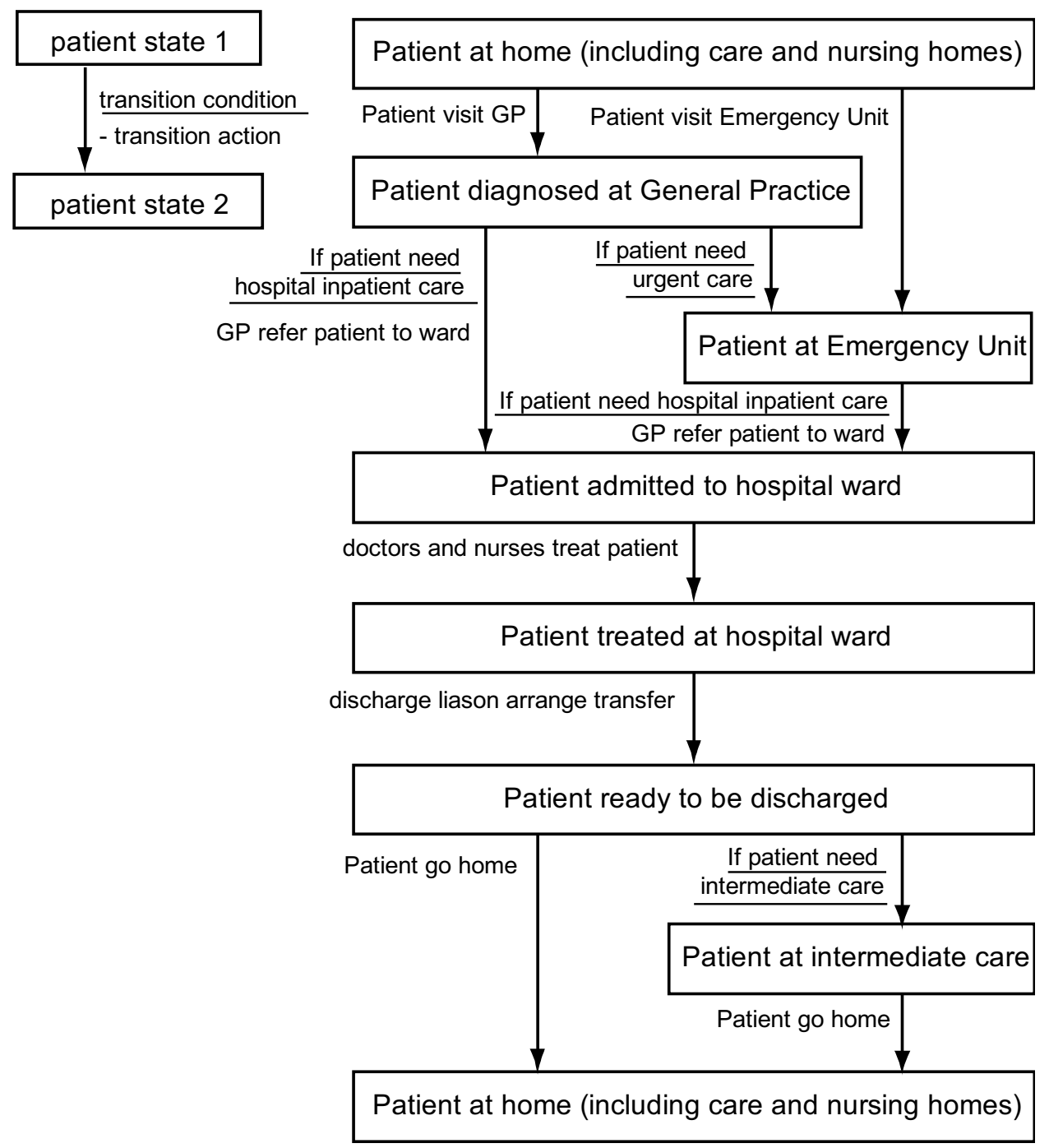

Figure 4: State machine diagram of a patient discharge process

\subsection{Stakeholders management}

There is a considerable literature on the role of stakeholders in projects; a useful summary can be found in Freeman et al (2010). In the application of PSMs in Stage 1, the issue of stakeholder identification and management is prominent at this early stage. As mentioned earlier, the involvement of those whose working lives will be impacted by any intervention needs to be more than merely accommodated. If an intervention is to be successful, then any approach should promote productive interactivity, both between different groups of stakeholders and between stakeholders and modeling professionals. In healthcare settings, one of the reasons why such interactivity might prove so challenging is the duration of the project, and the ensuing change of personnel. This seems to be a particular problem in the UK National Health Service (NHS), with high job turnover as key individuals switch roles (Connell 2001, Pouloudi and Whitley 1997). This has also been recognized in more recent work; for example, the EPSRC-funded RIGHT project explicitly sought to promote the active involvement of groups of stakeholders from across the UK, whose projects (and models for participation) would act as 'exemplars'. Many of the problems identified in Connell (2001) repeated themselves in these exemplars; a sufficiently wide representation of stake- 
holders was sometimes difficult to identify and recruit, and the longevity of the project was not always matched by that of the NHS post-holder, which undermined the productivity of some aspects of the interaction, however willing the intention.

\subsection{Definition of Output}

A particular challenge facing the use of PSMs is the difficulty in defining outputs within the context of problem structuring methods. Whilst some PSMs have specific outputs - for example Rich Pictures or Conceptual Models arising from SSM use, or diagrammatic or graphical representations from other approaches - as mentioned earlier, it is not always easy to see the relationships between these outputs and the following stages of the intervention. This is even more marked in some of the less tangible outputs; for example, the learning processes that often form part of the active participation, which often arise from the sort of informal exchanges such as the narratives described above, whilst useful for transferring knowledge between those who are present at PSM meetings, are not as easy to transfer to those who did not share firsthand the experiences - for some stories, 'you had to be there' for the outputs arising from them to make full sense or prove useful in later stages.

One lesson that might be learned from attempts at early use of PSM surrounds the idea of management of expectations. Often, PSM (in its encouragement of multiple perspectives) will appear to cloud rather than clear the troubled waters of a problem situation. The 'output' of such modeling is usually not a 'solution', but instead is a clearer insight into the problem situation. Such an output is sometimes difficult to express, notwithstanding its value.

\section{CONTINUITY OF MODELING}

As alluded to earlier, one important intended outcome, which might encourage the wider use of modeling at Stage 1 of any service development cycle, is the expectation that such approaches will increase the likelihood of user communities 'buying in' to any likely resolution of the issues. Much of the existing literature (for example, Checkland and Scholes 1990, Lehaney and Paul 1996, Brown 1997) supports this claim. One aspect of this increase in commitment is that those who have taken part in this stage will have gained a better appreciation of the views of a wider number of stakeholders. Perhaps more importantly, participants will have gained a deeper appreciation of the weight of the enthusiasm or reservations of other parties with whom they will need to work, whether such work is at the operational, day-to-day level (among, say clinical or other care-giving parties) or at a project management level (for example, the relationships between modeling professionals and their healthcare clients as the problem-in-hand is addressed).

The opportunities presented by graphical modeling approaches for continually re-examining a problem from various perspectives can lead to expansion and refinement of the entire thought process surrounding the problem. Thus, the misunderstanding and inconsistencies related to Stage 1 could be revealed. With a diagram that accurately reflects the current conceptualization of the problems, ideas and systems, the process of communicating can also be greatly improved. For example, issue maps could be particularly instrumental in exploring and clarifying problems and options, and identifying and communicating the areas where further analysis through modeling and simulation is needed. On the other hand, state machine diagrams could provide a good base for hard modeling approaches and simulation. It is also important to understand the roles each graphical modeling method can play at the different stages.

\section{CONCLUSIONS}

As can be seen from the above discussion, a number of benefits can be drawn from using these methods. Perhaps the most important benefit that can be realized is the process of consensual thought organization to drive modeling through the following stages. One of the main challenges that faces Stage 2 modeling is the lack of a common view and lack of a shared understanding of the problem. This can be attributed to the lack of a multiple stage view of the life cycle of the service. For modeling to have a more viable im- 
pact on healthcare service, it has to start from the root of the service. Even if the intervention of modeling takes place while the service is at Stage 2, it would be important to use Stage 1 modeling approaches to focus and organize the thoughts of the stakeholders.

In this paper we have started with the assumption that a typical healthcare service goes through three main stages throughout its life cycle. We then consolidated this argument and defined the modeling requirements for each stage. Modelers need to recognize these stages and the connection between them. The literature suggests that there is disconnection between Stage 1 and Stage 2 modeling practices. In this paper we introduce the potential values of modeling and modeling approaches at Stage 1 and the potential benefits that can be carried over to Stage 2 .

\section{REFERENCES}

Bracewell, R.H. and K.M. Wallace. 2003. A tool for capturing design rationale. 14th International Conference on Engineering Design (ICED'03). Stockholm, Sweden.

Brailsford, S.C. 2008. System dynamics: what's in it for healthcare simulation modelers. In Proceedings of the 2008 Winter Simulation Conference, ed. S.J. Mason, R.R. Hill, L. Mönch, O. Rose, T. Jefferson, and J.W. Fowler ,1478-1483. Piscataway, New Jersey: Institute of Electrical and Electronics Engineers, Inc.

Brown, A.D. 1997. Developing a purchasing strategy: a case study of a District Health Authority using soft systems methodology. Health Services Management Research 10:58 - 68.

Checkland, P.B. 1981. Systems thinking, systems practice. Chichester, UK: Wiley.

Checkland, P.B. and J. Scholes. 1990. Soft systems methodology in action. Chichester, UK: Wiley.

Clarkson, P.J., P. Buckle, R. Coleman, D. Stubbs, J. Ward, J. Jarrett, R. Lane, and J. Bound. 2004. Design for patient safety: a review of the effectiveness of design in the UK health service. Journal of Engineering Design 15:123-140.

Conklin, J., A. Selvin, S. Buckingham Shum, and M. Sierhuis. 2001. Facilitated hypertext for collective sensemaking: 15 Years on from IBIS. Proceedings 12th ACM Conference on Hypertext and Hypermedia. Århus, Denmark.

Connell, N.A.D. 2001. Evaluating soft OR: some reflections on an apparently "unsuccessful" implementation using an SSM based approach. Journal of the Operational Research Society 52:150 - 160.

Connell, N.A.D., J.H. Klein, and E. Meyer. 2004. Narrative approaches to the transfer of organisational knowledge. Knowledge Management Research and Practice 2:184-193.

Crilly, N., P. Clarkson, and A.F. Blackwell. 2006. Graphic elicitation: using research diagrams as interview stimuli. Qualitative Research 6:341-366.

Eldabi, T. 2009. Implementation issues of modeling healthcare problems: misconceptions and lessons. In Proceedings of the 2009 Winter Simulation Conference, ed. M.D. Rossetti, R.R. Hill, B. Johansson, A. Dunkin and R.G. Ingalls,1831-1839. Piscataway, New Jersey: Institute of Electrical and Electronics Engineers, Inc.

Eldabi, T., R.J. Paul, and T. Young. 2007. Simulation modelling in healthcare: reviewing legacies and investigating futures. Journal of the Operational Re-search Society 58:262-270.

Freeman, R.E., J.S. Harrison, A.C. Wicks, B.L. Parmar, and S. De Colle. 2010. Stakeholder theory: the state of the art. Cambridge, UK: Cambridge University Press.

Friedenthal, S., A. Moore, and R. Steiner. 2008. A Practical Guide to SysML: The Systems Modeling Language. US: Morgan Kaufmann.

Johne, A., and C. Storey. 1998. New service development: a review of the literature and annotated bibliography. European Journal of Marketing 32:184-251.

Jun, J.B., S.H. Jacobson, and J.R. Swisher. 1999. Application of discrete-event simulation in health care clinics: a survey. Journal of the Operational Research Society 50:109-23.

Jun, G.T., J. Ward, and P.J. Clarkson. 2010. Systems modelling approaches to the design of safe healthcare delivery: ease of use and usefulness perceived by healthcare workers. Ergonomics, In Press. 
Klein, J.H., N.A.D. Connell, and E. Meyer. 2007. Operational research practice as storytelling. Journal of the Operational Research Society 58:1535-1542.

Kunz, W., and H.W.J. Rittel. 1970. Issues as elements of information systems. Working Paper 131. Institute of Urban and Regional Development, University of California, Berkeley, California.

Lehaney, B., and R.J. Paul. 1996. The use of SSM in the development of a simulation of out-patient services at Watford General Hospital. Journal of the Operational Research Society 47: 864 -870.

Menor, L.J., M.V. Tatikonda, and S.E. Sampson. 2002. New service development: areas for exploitation and exploration. Journal of Operations Management 20:135-157.

Pidd, M. 2007. Making sure you tackle the right problem: linking hard and soft methods in simulation practice. In Proceedings of the 2007 Winter Simulation Conference, ed. S.G. Henderson, B. Biller, M.-H.Hsieh, J. Shortle, J.D. Tew, and R.R. Barton, 195-204. Piscataway, New Jersey: Institute of Electrical and Electronic Engineers, Inc.

Pouloudi, A., and E.A. Whitley. 1997. Stakeholder identification in inter-organizational systems: gaining insights for drug use management system. European Journal of Information Systems 6:1-14.

Royston, G. 2005. Modelling and simulation in health potential, achievement and challenge. Presentation for MASHnet launch, September 2005. Available via <http://www.pms.ac.uk/mashnet/index •php?secti on=sub\&act=MA.SHnet Launc hReport20.Sep 05\#RoystonTalk> [accessed February, 17 2006].

Wenger, E. 1998. Communities of practice: learning, meaning, and identity. Cambridge: Cambridge University Press.

\section{AUTHOR BIOGRAPHIES}

TILLAL ELDABI is a senior lecturer at Brunel Business School, Brunel University, UK. He has B.Sc. in Econometrics and Social Statistics, M.Sc. in Simulation Modeling and Ph.D. in Simulation Modeling in Healthcare . His research is into aspects of healthcare modeling and simulation. He developed a number of models and bespoke packages to support health economists and clinicians to decide on best treatment programs. Dr Eldabi has published widely in the field of modeling in healthcare and edited a number of special issues in highly respectable journals. Dr. Eldabi's email address is <tillal.eldabi@brunel.ac.uk>.

THOMAS JUN is a Research Associate in the Engineering Design Centre at the University of Cambridge. His research interest is in integrating mapping, modeling and simulation approaches for healthcare service design. As well as publishing academic papers for both healthcare and design audience, he has produced a practical workbook (modeling and simulation techniques for supporting healthcare decision making) for healthcare practitioners. Dr. Jun's email address is $\langle$ gj 225 @ cam.ac.uk $\rangle$.

N.A.D. (CON) CONNELL is Professor of Management in the School of Management, University of Southampton. He has researched and published widely in healthcare-related topics, including articles in BMJ, Health Services Management Research, Journal of the OR Soc, Journal of Health Organisation \& Management, and Journal of Advanced Nursing. Professor Connell's email address is $<$ n.a.conneliesoton.ac.uk $>$.

JOHN CLARKSON is a Professor of Engineering Design and Director of the Cambridge Engineering Design Centre. His research interests are in the development of design methodologies to address specific design issues, for example, process management, change management, healthcare design and inclusive design. As well as publishing over 450 papers, he has written and edited a number of books on medical

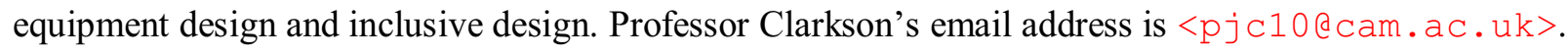


JONATHAN H. KLEIN is a Senior Lecturer and Director of Undergraduate Programmes in the School of Management at the University of Southampton. His research interests include knowledge sharing, communities of practice, and the methodology of management science. Dr. Klein's email address is $<j \cdot h \cdot k l e i n d s o t o n \cdot a c \cdot u k>$. 